\title{
A novel somatic FGFR3 mutation in primary lung cancer
}

\author{
KAZUYA SHINMURA $^{1}$, HISAMI KATO ${ }^{1}$, SHUN MATSUURA ${ }^{1,2}$, YUSUKE INOUE $^{1,2}$, HISAKI IGARASHI ${ }^{1}$, \\ KIYOKO NAGURA $^{1}$, SATOKI NAKAMURA ${ }^{1}$, KYOKO MARUYAMA ${ }^{1}$, MARI TAJIMA ${ }^{1}$, KAZUHITO FUNAI ${ }^{3}$, \\ HIROSHI OGAWA ${ }^{4}$, MASAYUKI TANAHASHI ${ }^{5}$, HIROSHI NIWA ${ }^{5}$ and HARUHIKO SUGIMURA ${ }^{1}$ \\ Departments of ${ }^{1}$ Tumor Pathology, ${ }^{2}$ Internal Medicine 2 and ${ }^{3}$ Surgery 1, Hamamatsu University School of Medicine, \\ Hamamatsu, Shizuoka 431-3192; Divisions of ${ }^{4}$ Pathology and ${ }^{5}$ Thoracic Surgery, Respiratory Disease Center, \\ Seirei Mikatahara General Hospital, Hamamatsu, Shizuoka 433-8558, Japan
}

Received October 9, 2013; Accepted November 25, 2013

DOI: $10.3892 /$ or.2014.2984

\begin{abstract}
The recent discovery of mutations and fusions of oncokinase genes in a subset of lung cancers (LCs) is of considerable clinical interest, since LCs containing such mutations or fusion transcripts are reportedly sensitive to kinase inhibitors. To better understand the role of the recently identified fibroblast growth factor receptor 3 (FGFR3) mutations and fusions in pulmonary carcinogenesis, we examined 214 LCs for mutations in the mutation cluster region of the FGFR 3 gene using sequencing analysis. We also examined 190 LCs for the FGFR3-TACC3 and FGFR3-BAIAP2L1 fusion transcripts using reverse transcription-polymerase chain reaction (RT-PCR) analysis. Although the expression of FGFR3-TACC3 and FGFR3-BAIAP2L1 fusion transcripts was not detected in any of the carcinomas, somatic FGFR3 mutations were detected in two $(0.9 \%)$ LCs. The two mutations were the same, i.e., p.R248H. That was a novel mutation occurring in the same codon as p.R248C, for which an oncogenic potential has previously been shown. Increased FGFR3 expression was shown in the two LCs containing the FGFR3 p. R248H mutation using qPCR. Histologically, both carcinomas were squamous cell carcinomas, therefore the incidence of the FGFR3 mutation among the squamous cell carcinoma cases was calculated as $3.2 \%(2 / 63)$. When we examined other co-occurring genetic abnormalities, one case exhibited a p53 p.R273C mutation, while the other case exhibited PIK3CA and $S O X 2$ amplifications. The above results suggest that an FGFR 3 p.R248H mutation is involved in the carcinogenesis of a subset of LCs and may contribute to the elucidation of the characteristics of FGFR3 mutation-positive LCs in the future.
\end{abstract}

Correspondence to: Dr Kazuya Shinmura, Department of Tumor Pathology, Hamamatsu University School of Medicine, 1-20-1 Handayama, Higashi Ward, Hamamatsu, Shizuoka 431-3192, Japan E-mail: kzshinmu@hama-med.ac.jp

Key words: fibroblast growth factor receptor 3, somatic mutation, fusion gene, lung cancer, squamous cell carcinoma

\section{Introduction}

Mutations of EGFR, KRAS, PIK3CA, and others, and fusion transcripts of ALK, ROS1 and RET are oncogenic alterations in lung cancers (LCs) and some of them are therapeutic targets (1-8). For example, crizotinib, a small molecule inhibitor of ALK, has been shown to selectively inhibit the growth of ALK-positive LC (9), meaning that a subclass of LC patients are likely to benefit clinically from an ALK inhibitor. Therefore, targetable oncogenic alterations in LCs may have a significant clinical impact.

Fibroblast growth factor receptor 3 (FGFR3) has been revealed to be activated by the mutation or fusion of its own gene in several types of cancer, such as urinary bladder cancer, glioblastoma, rhabdomyosarcoma and LC (10-17). Some tumor-specific FGFR3 mutations, including p.R248C and p.S249C, drive the anchorage-independent growth of NIH3T3 cells and tumor formation in xenograft models, and cells harboring such FGFR3 mutations showed an enhanced sensitivity to BGJ398, a selective FGFR kinase inhibitor (17). Regarding fusions, FGFR3-TACC3 and FGFR3-BAIAP2L1 oncogenic fusions have thus far been identified (13-15), and cells harboring the FGFR3-TACC3 fusion showed enhanced sensitivity to three FGFR kinase inhibitors, including BGJ398 (13). Thus, oncogenic FGFR3 mutations and fusions in tumors can be therapeutic targets. To determine which patients can benefit from FGFR inhibitors in the future, the incidence of FGFR 3 mutations or fusions in various tumors derived from patients from various demographic areas must be determined. However, to date, only a few studies have been published regarding FGFR 3 mutations and fusions in LC and Asian patients with LC have not yet been analyzed $(12,16,17)$. Notably, according to previous reports $(12,16,17)$, the only experimentally proven oncogenic FGFR3 mutations in LCs are p.R248C and p.S249C, which are located within the first ten bases of exon 7. Therefore, we considered this region to be a mutation cluster region in LCs. In the present study, to determine the status of FGFR3 mutation and fusion in LCs derived from Japanese patients, we examined LCs from Japanese patients for the mutations in the mutation cluster region of FGFR3 and the expression of FGFR3-TACC 3 and FGFR3-BAIAP2L1 fusion transcripts and pathologically and molecularly characterized LCs containing such an alteration. 
This is the first published study to describe FGFR3 mutations in LCs derived from Japanese patients.

\section{Materials and methods}

Primary $L C$. Samples of surgical specimens were obtained from 362 Japanese LC patients who underwent surgery for cancer at Hamamatsu University Hospital and Mikatahara Seirei General Hospital. Informed consent was obtained from all the patients, and the study was approved by the Institutional Review Boards (IRBs) of Hamamatsu University School of Medicine and Mikatahara Seirei General Hospital. The clinicopathological profiles of the cases are shown in Table I. The histological classification was based on the World Health Organization system. Among the 362 cases, 214 cases were used in the mutational analysis, whereas 190 cases were used in the reverse transcription-polymerase chain reaction (RT-PCR) analysis; 42 cases were used in both analyses.

Search for FGFR3 mutations using PCR-sequencing. Genomic DNAs were extracted from the lung tissue samples using a DNeasy kit (Qiagen, Valencia, CA, USA) and were examined for somatic mutations in the DNA sequences (the first half of exon 7) covering the mutation cluster region in the FGFR 3 gene. PCR was performed in $20-\mu 1$ reaction mixtures containing HotStarTaq DNA polymerase (Qiagen) under the following conditions: $30 \mathrm{sec}$ at $94^{\circ} \mathrm{C}, 30 \mathrm{sec}$ at $65^{\circ} \mathrm{C}$ and $60 \mathrm{sec}$ at $72^{\circ} \mathrm{C}$ for 45 cycles. The following set of primers was used: 5'-CTG AGC GTC ATC TGC CCC C-3' and 5'-TGG GGC TGT GCG TCA CTG TAC-3'. PCR-amplified products were purified with ExoSAP-IT (GE Healthcare Bio-Sciences, Piscataway, NJ, USA) and were sequenced directly using a BigDye Terminator Cycle Sequencing Reaction kit (Applied Biosystems, Tokyo, Japan) and the ABI 3130 Genetic Analyzer (Applied Biosystems).

Search for FGFR3 fusion transcripts using RT-PCR. Total RNA was extracted from the lung tissue samples using an RNeasy kit (Qiagen) and was converted to first-strand cDNA using a SuperScript First-Strand Synthesis System for RT-PCR (Invitrogen, Carlsbad, CA, USA) according to the supplier's protocol. PCR was performed in $20-\mu 1$ reaction mixtures containing HotStarTaq DNA polymerase under the following conditions: $30 \mathrm{sec}$ at $94^{\circ} \mathrm{C}, 30 \mathrm{sec}$ at $59^{\circ} \mathrm{C}$ and $60 \mathrm{sec}$ at $72^{\circ} \mathrm{C}$ for 45 cycles. The following reverse PCR primers were used: 5'-CAG CCT CCA CTG GTT TCT GTA G-3' for the sequence at exon 4 of TACC 3, 5'-TGG TAC ACA ACC TCT TCG AAC C-3' for the sequence at exon 12 of TACC3, and 5'-GGA CAT GTC CCA GTT CAG TTG-3' for the sequence at exons 3 and 4 of BAIAP2L1. The forward PCR primer used was the same, i.e., 5'-GAC CGT GTC CTT ACC GTG AC-3' for the sequence at exon 18 of FGFR3. The PCR products were fractionated using electrophoresis on an agarose gel and were stained with ethidium bromide.

Quantitative RT (qRT)-PCR. The expressions of the FGFR3 mRNA transcripts were measured using real-time qRT-PCR with a LightCycler instrument (Roche, Palo Alto, CA, USA). PCR amplification of the FGFR3 transcript and the transcript of the control housekeeping gene $G A P D H$ was performed with
Table I. Summary of the clinicopathological profiles of the patients.

\begin{tabular}{lccc}
\hline & \multicolumn{3}{c}{ Number $^{\mathrm{a}}$} \\
\cline { 2 - 4 } Characteristics & Total & $\begin{array}{c}\text { Mutational } \\
\text { analysis }\end{array}$ & $\begin{array}{c}\text { RT-PCR } \\
\text { analysis }\end{array}$ \\
\hline $\begin{array}{l}\text { No. of patients } \\
\text { Age, years (mean } \pm \text { SD) }\end{array}$ & $66.5 \pm 9.6$ & $66.4 \pm 9.7$ & $66.9 \pm 9.9$ \\
Gender, n (\%) & & & 190 \\
Male & $259(71.5)$ & $157(73.4)$ & $134(70.5)$ \\
Female & $103(28.5)$ & $57(26.6)$ & $56(29.5)$ \\
Histology, n (\%) & & & \\
$\begin{array}{l}\text { Adenocarcinoma } \\
\text { Squamous cell }\end{array}$ & $210(58.0)$ & $125(58.4)$ & $109(57.4)$ \\
carcinoma & $110(30.4)$ & $63(29.4)$ & $60(31.6)$ \\
$\begin{array}{l}\text { Large cell carcinoma } \\
\text { Small cell carcinoma }\end{array}$ & $13(3.6)$ & $9(4.2)$ & $5(2.6)$ \\
$\begin{array}{l}\text { Adenosquamous } \\
\text { carcinoma }\end{array}$ & $12(3.3)$ & $11(5.1)$ & $3(1.6)$ \\
Pleomorphic carcinoma & $6(1.7)$ & $2(0.9)$ & $4(2.1)$ \\
\hline
\end{tabular}

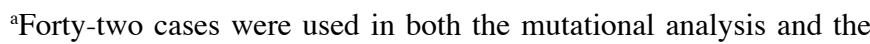
RT-PCR analysis. SD, standard deviation. RT-PCR, reverse transcription-polymerase chain reaction.

the cDNA and a QuantiTect SYBR Green PCR kit (Qiagen). The following PCR primers were used: 5'-GCA CAC ACG ACC TGT ACA TGA TC-3' and 5'-CCA GGT ACT CGT CGG TGG AC-3' for the FGFR3 transcript, and 5'-GCT CAG ACA CCA TGG GGA AG-3' and 5'-TGT AGT TGA GGT CAA TGA AGG GG-3' for the GAPDH transcript. The T/N ratios were calculated by dividing the normalized transcript amounts in the cancerous tissue by the amounts in the non-cancerous tissue.

Immunohistochemical staining. Sections of formalin-fixed, paraffin-embedded tissue samples were used for immunohistochemical staining using a Histofine Simple Stain MAX PO kit (Nichirei, Tokyo, Japan), as previously described (18). The primary antibodies were: anti-CK14, anti-thyroid transcription factor-1 (TTF-1) (both from Novocastra Laboratories, Newcastle, UK) and anti-p53 (clone DO7; Dako, Tokyo, Japan). Hematoxylin and eosin (H\&E) staining was also performed.

Search for EGFR, KRAS, PIK3CA and p53 mutations using $P C R$-sequencing. Genomic DNA derived from the lung tissue samples containing an FGFR 3 mutation was examined for somatic mutations in the DNA sequences of mutation cluster regions in the EGFR, KRAS, PIK3CA and $p 53$ genes. PCR amplification was performed as previously described (7). Sequencing was performed as described in the 'Search for FGFR3 mutations using PCR-sequencing' section.

Fluorescence in situ hybridization (FISH) analysis. Paraffinembedded tissue sections were de-waxed and re-hydrated, then 
boiled in $0.01 \mathrm{M}$ citrate buffer ( $\mathrm{pH}$ 6.0) to release the closed chromosomal structures. A combination of Cy3-labeled bacterial artificial chromosome (BAC) clone (RP11-100B16) for the FGFR 1 locus, BAC clone (RP11-245C23 and RP11-355N16) for the PIK3CA locus, or BAC clone (RP11-275H4) for the SOX2 locus and a SpectrumGreen-labeled control BAC probe for the near centromere locus on chromosome 3 or 8 were placed on a slide and covered with a coverslip. All the BAC probes were obtained from Advanced GenoTechs Co. (Tsukuba, Japan). The slides with the hybridization mixture were denatured on a digital hot plate (HP-15; As One Corporation, Osaka, Japan) and then incubated overnight at $42^{\circ} \mathrm{C}$. After washing the slide in $50 \%$ formamide/2X SSC, mounting medium containing DAPI (Vector Laboratories, Burlingame, CA, USA) was used for nuclear counterstaining. The slides were promptly examined under a fluorescence microscope (Olympus BX51-FL; Olympus, Tokyo, Japan) equipped with epifluorescence filters and a photometric CCD camera (Sensicam; PCO Company, Kelheim, Germany). The images captured were digitized and stored in the image analysis program (MetaMorph; Molecular Devices, Palo Alto, CA, USA). The average ratio of the FGFRI, $P I K 3 C A$, or SOX2 signal number to the control probe signal number was calculated for each cancer. If the ratio of a cancer was $>2.5$, the cancer was defined as amplification-positive.

\section{Results}

In the present study, we examined $214 \mathrm{LCs}$ for mutations in the mutation cluster region of the FGFR 3 gene using a sequencing analysis; we also examined 190 LCs for FGFR3-TACC3 and FGFR3-BAIAP2L1 fusion transcripts using an RT-PCR analysis. Although the expression of FGFR3-TACC3 and FGFR3-BAIAP2L1 fusion transcripts was not detected in any of the carcinomas, FGFR 3 mutations were detected in two $(0.9 \%)$ LCs (Fig. 1A). The mutations that occurred in the LCs derived from cases no. 57 and no. 183 were the same, i.e., a somatic c. $743 \mathrm{G}>\mathrm{A}$ mutation associated with an amino acid exchange from Arg to His at codon 248. The p.R248H mutation in the FGFR3 gene has not been previously reported, suggesting it is a novel mutation. Of note, with regards to codon 248 , it was previously reported that the p.R248C mutation drives cellular transformation (17), indicating that the p.R248H mutation may have an oncogenic potential similar to that of the p.R248C mutation. When we next examined the expression levels of FGFR3 mRNA transcripts in the two LCs containing an FGFR 3 p.R248H mutation using a qRT-PCR analysis, the ratio of the level of FGFR3 mRNA expression in the cancerous tissue to the level in the corresponding non-cancerous tissue ( $\mathrm{T} / \mathrm{N}$ ratio) was increased in both cases (Fig. 1B), suggesting the involvement of mutated FGFR3 in LC. Case no. 57 was a 62-year-old man who was a smoker [Brinkman index $(\mathrm{BI})=1,800]$ and case no. 183 was a 66 -year-old man who was also a smoker $(\mathrm{BI}=1,000)$. The histological classification of both LCs was squamous cell carcinoma (Fig. 2A and B). An immunohistochemical study revealed that the carcinomas were positive for CK14 but negative for TTF-1 (Fig. 2C and D, Table II), indicating that the immunophenotype of the carcinoma was compatible with that of squamous cell carcinoma. Among the 214 cases used for the mutational analysis, 63 cases were histologically classified as
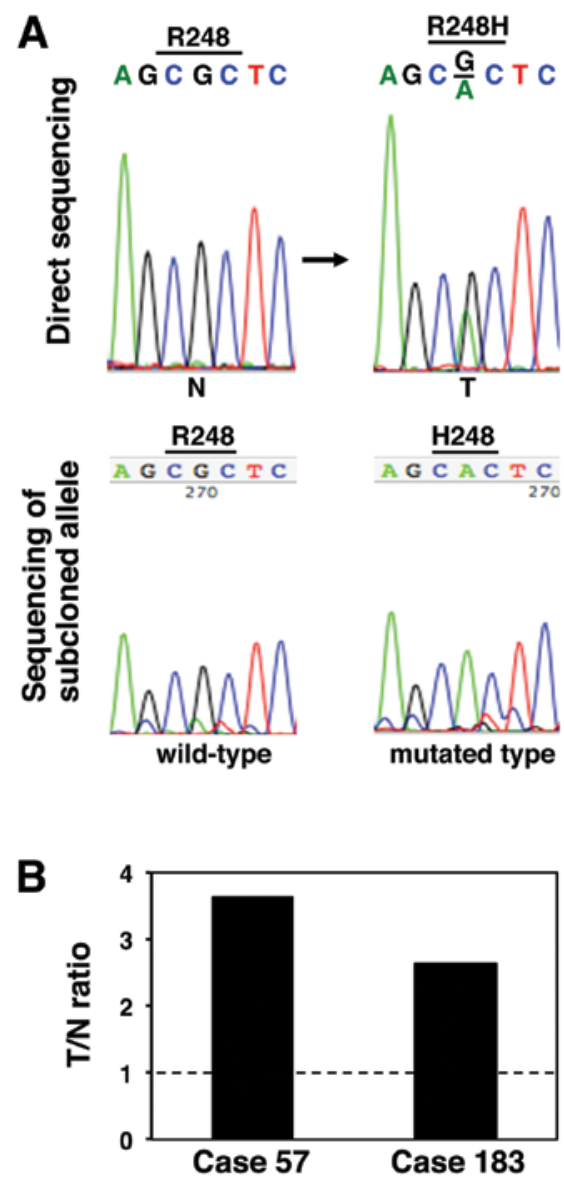

Figure 1. Detection of FGFR3 mutations in primary lung cancer (LC). (A) Results of direct sequencing analysis of the FGFR3 gene in LC DNA derived from case no. 183 (upper panels) and results of sequencing analysis of the subcloned PCR product covering the mutation in the case (lower panels). A somatic C $\underline{G} C$ to $\mathrm{CAC}$ mutation associated with the conversion from Arg to His at codon 248 was detected in the LC. N, non-cancerous lung tissue DNA; $\mathrm{T}$, cancerous lung tissue DNA. In the analysis of subcloned products, both wild-type and mutated-type alleles were detected. (B) Comparison between FGFR3 mRNA expression in cancerous tissues from two LCs containing an FGFR3 mutation and corresponding non-cancerous lung tissues, as determined using a qRT-PCR analysis. After normalizing the amounts of FGFR3 transcripts to those of the GAPDH transcripts, the T/N values were calculated by dividing the amount of normalized transcripts in the cancerous tissue by the amount in the corresponding non-cancerous tissue. FGFR3, fibroblast growth factor receptor 3 .

squamous cell carcinoma; thus, the incidence of the FGFR3 mutation among the squamous cell carcinoma cases was 3.2\% (2/63). These findings suggest that a subset of LC may carry an FGFR 3 mutation.

We next examined whether the LC cases containing the FGFR 3 p.R248H mutation also contained mutations in other genes that are often mutated in $\operatorname{LC}(3,8,12,19,20)$. Mutation cluster regions for $E G F R, K R A S, P I K 3 C A$ and $p 53(3,8,12,19,20)$ were searched for somatic mutations. No somatic mutations in exon 2 of $K R A S$, exons 19 and 21 of $E G F R$, or exons 9 and 20 of $P I K 3 C A$ were detected; however, a somatic c. $817 \mathrm{C}>\mathrm{T}$ mutation associated with an amino acid exchange from Arg to Cys at codon 273 (p.R273C) was detected in the $p 53$ gene in case no. 183 (Fig. 2E, Table II). The fact that the missense mutation was detected in the DNA binding region of the p53 protein suggested that the mutant p53 protein was stable in the cancer 

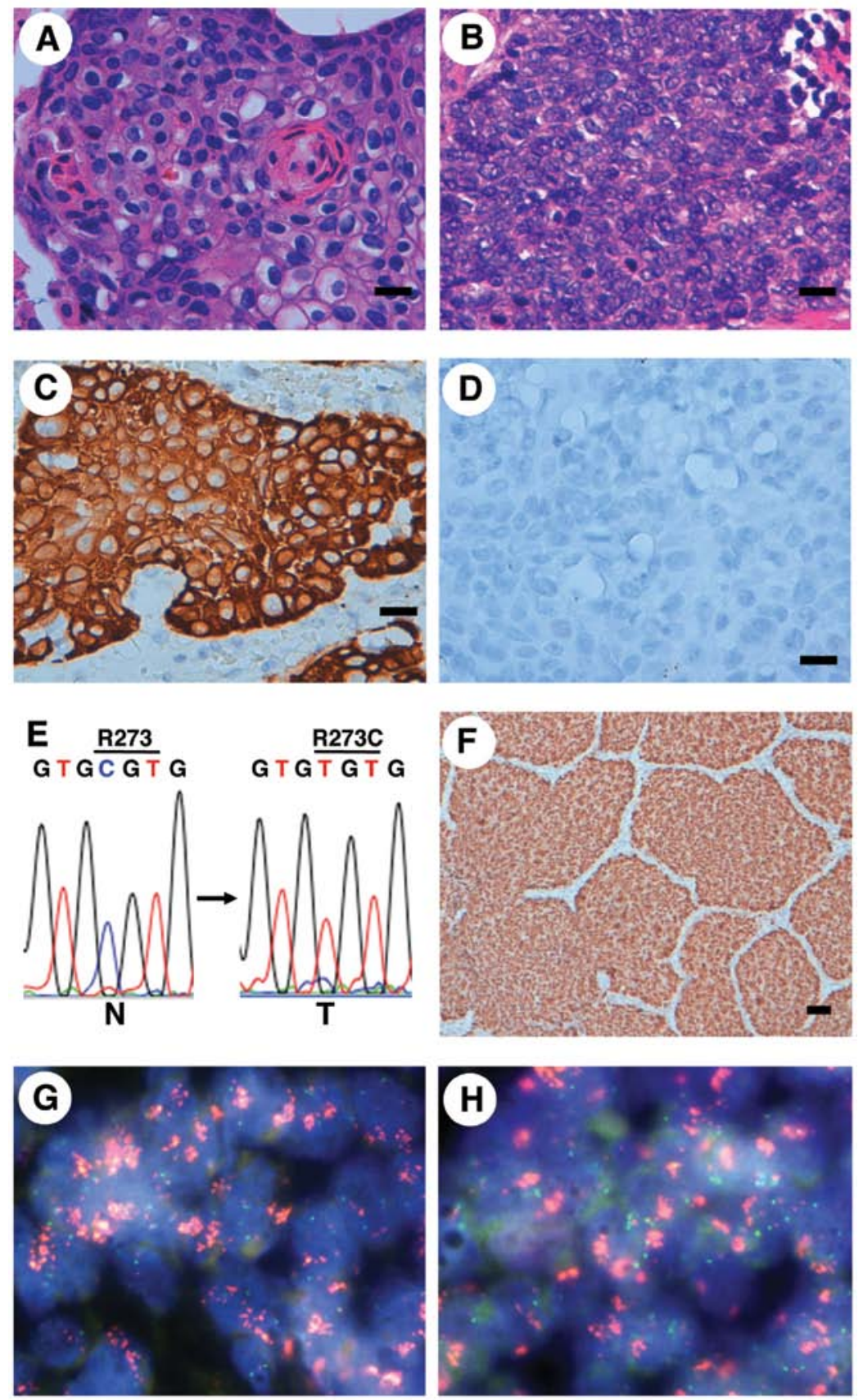

Figure 2. Pathological, immunohistochemical, mutational and FISH analyses for lung cancers (LCs) containing an FGFR3 mutation. (A and B) Microscopic image (H\&E) of the squamous cell carcinoma in case no. 57 (A) and case no. 183 (B). Scale bar, $20 \mu \mathrm{m}$. (C and D) The squamous cell carcinoma of case no. 57 was immunohistochemically positive for CK14 (C) and negative for TTF-1 (D). Scale bar, $20 \mu \mathrm{m}$. (E) Detection of a somatic $p 53$ missense mutation in LC from case no. 183. A CGT to TGT mutation associated with the conversion from Arg to Cys at codon 273 was detected in the LC. N, non-cancerous lung tissue DNA; T, cancerous lung tissue DNA. (F) Immunohistochemical detection of p53 accumulation in the LC from case no. 183 . Scale bar, $50 \mu \mathrm{m}$. $(\mathrm{G}$ and $\mathrm{H})$ PIK3CA $(\mathrm{G})$ and SOX2 $(\mathrm{H})$ amplifications in LC from case no. 57, as shown using a FISH analysis. Red signals, BAC probe for the PIK3CA (G) and SOX2 (H) locus; green signals, control probe for the near centromere locus on chromosome 3. FGFR3, fibroblast growth factor receptor 3; H\&E, hematoxylin and eosin; TTF-1, thyroid transcription factor-1.

cells. We therefore performed immunohistochemical staining for p53 in case no. 183 and the results showed the nuclear accumulation of p53 exclusively in the cancer cells (Fig. 2F). These results suggested that a somatic $p 53$ mutation, but not EGFR, KRAS or PIK3CA mutations, may occur in a subset of LCs containing an FGFR 3 mutation.

We also examined whether the LC cases containing the FGFR 3 p.R248H mutation also contained gene amplifications, which are frequently observed in $\mathrm{LC}(12,21,22)$. The amplification status of the FGFR1, PIK3CA and SOX2 genes was examined using a FISH analysis. Although FGFRI amplification was not detected in either case, the amplification of the PIK3CA and SOX2 genes was detected in case no. 57 (Fig. $2 \mathrm{G}$ and $\mathrm{H}$, Table II). These results suggested that $P I K 3 C A$ and SOX2 gene amplification, but not FGFR1, may occur in a subset of LCs containing an FGFR3 mutation. 
Table II. Clinical profiles of the cases with LC containing an FGFR3 mutation and the pathological, immunohistochemical, mutational and amplification status of the LCs.

\begin{tabular}{lll}
\hline Characteristics & \multicolumn{1}{c}{ Case No. 57} & \multicolumn{1}{c}{ Case No. 183} \\
\hline FGFR3 mutation & p.R248H & p.R248H \\
Age (years) & 62 & 66 \\
Gender & Male & Male \\
Smoking habit & Smoker (BI=1,800) & Smoker (BI=1,000) \\
Histology & Squamous cell carcinoma & Squamous cell carcinoma \\
Stage & III & II \\
Lymph node metastasis & Positive & Positive \\
CK14 expression & Positive & Positive \\
TTF-1 expression & Negative & Negative \\
EGFR mutation (exons 19 and 21) & Wild-type & Wild-type \\
KRAS mutation (exon 2) & Wild-type & Wild-type \\
$P I K 3 C A$ mutation (exons 9 and 20) & Wild-type & Wild-type \\
p53 mutation (exons $4-9)$ & Wild-type & p.R273C mutation \\
$F G F R 1$ amplification & Amplification (-) & Amplification (-) \\
$P I K 3 C A$ amplification & Amplification $(+)$ & Amplification $(-)$ \\
SOX2 amplification & Amplification $(+)$ & Amplification (-) \\
\hline
\end{tabular}

BI, Brinkman index; LC, lung cancer; FGFR3, fibroblast growth factor receptor 3;TTF-1, thyroid transcription factor-1.

\section{Discussion}

In the present study, FGFR3 mutations were found in two $(0.9 \%)$ of the $214 \mathrm{LCs}$ that were examined, but the expression of FGFR3-TACC3 and FGFR3-BAIAP2L1 fusion transcripts was not detected in any of the $190 \mathrm{LCs}$ that were examined. Both LCs containing an FGFR3 mutation were histologically diagnosed as squamous cell carcinoma, and squamous cell carcinoma accounted for 63 out of the 214 LCs examined in the mutational analysis, resulting in an incidence of $F G F R 3$ mutation among squamous cell carcinoma cases of $3.2 \%$ (2/63). Both of the mutations were p.R248H, which was a novel mutation located in the same codon as the oncogenic p.R248C mutation. Both LCs exhibited an increased FGFR3 expression, suggesting the involvement of mutated FGFR3 in LC. Regarding the co-occurring genetic abnormalities, one case exhibited a $p 53$ p.R273C mutation, while the other case exhibited PIK3CA and SOX2 amplifications. No somatic mutations were detected in the mutation cluster regions of the EGFR, KRAS and PIK3CA genes in either case. These results suggested that an FGFR 3 p.R $248 \mathrm{H}$ mutation is involved in the carcinogenesis of a subset of LCs.

A novel p.R248H mutation in the FGFR3 gene was detected in two lung squamous cell carcinomas derived from Japanese patients with a smoking habit. The detection of the p.R248H mutation in two LCs suggests a recurrent mutation in LC. The p.R248C mutation occurred in the same codon as the p.R248H mutation and was previously shown to drive cellular transformation; additionally, the transformation was shown to be reversed by a small molecule FGFR inhibitor (17). Moreover, the p.R248C mutation was detected not only in LC, but also in urinary bladder cancer and multiple myeloma $(10,11,23)$. Regarding the amino acid conversion from Arg to His,
p.R175H and p.R273H in the $p 53$ gene are hotspot mutations and gain-of-function mutations $(24,25)$, suggesting the effect of the amino acid exchange on carcinogenesis. In addition, the screening for non-acceptable polymorphisms (SNAP) program, which predicts the effect of single amino acid substitutions on protein function (http://www.rostlab.org/services/SNAP) (26), predicted that the $F G F R 3$ p.R248H mutation was non-neutral. Finally, in our qRT-PCR experiment, an increased FGFR3 expression was detected in both LCs containing a p.R248H mutation. Thus, the FGFR 3 p.R248H mutation may play an important role in the genesis and development of LCs. In the future, a precise functional investigation may aid in clarifying the role of the FGFR 3 p.R248H mutation.

There have been two previous reports investigating FGFR 3 mutations. Activating FGFR 3 mutations were detected at a frequency of $2.2 \%$ (4/178 squamous cell carcinomas) in one study (12) and 4.2\% (2/48 squamous cell carcinomas) in another report (16). In the present study, the incidence of FGFR3 mutation among squamous cell carcinomas derived from Japanese patients was 3.2\%, although functional characterization of the mutant was not performed. These results suggested that FGFR 3 mutation is a recurrent event in lung squamous cell carcinomas in multiple populations.

FGFR3 fusion transcripts were previously found in one study at a frequency of $4.2 \%$ (2/48 squamous cell carcinomas) (16). On the other hand, no FGFR3 fusion transcripts were detected in our cases, suggesting that FGFR3 fusion may be rare in the Japanese population. However, since the number of analyzed squamous cell carcinoma cases in our study was relatively small $(n=60)$ and FGFR3 may be fused with proteins other than TACC 3 and BAIAP2L1, a future large study examining this issue is required to examine the incidence of FGFR3 fusion in LCs derived from Japanese patients. 
In our FGFR3 mutation-positive cases, the co-occurrence of p53 mutation in one case and the co-occurrence of PIK3CA and $S O X 2$ amplification in the other case were observed. Both p53 mutation and amplification of the PIK3CA and SOX2 genes are frequent in lung squamous cell carcinoma $(12,21,22)$. These results suggest that a combination of FGFR3 mutation and such alterations may favor lung squamous cell carcinoma and FGFR3 mutation is not mutually exclusive with such alterations in lung squamous cell carcinoma.

In conclusion, our FGFR3 mutation-positive LCs in conjunction with previously detected FGFR3 mutation-positive LCs suggested that an FGFR3 mutation is involved in the carcinogenesis of a subset of LCs, especially lung squamous cell carcinomas, and may aid in elucidating the characteristics of FGFR3 mutation-positive LCs in the future.

\section{Acknowledgements}

The authors wish to acknowledge Mr. T. Kamo (Hamamatsu University School of Medicine) for his technical assistance. The present study was supported in part by a grant-in-aid from the Ministry of Health, Labour and Welfare (21-1), a grantin-aid from the Japan Society for the Promotion of Science (25460476), a grant-in-aid from the Ministry of Education, Culture, Sports, Science and Technology (221S0001), and the Smoking Research Foundation.

\section{References}

1. Soda M, Choi YL, Enomoto M, Takada S, Yamashita Y, Ishikawa S, Fujiwara S, Watanabe H, Kurashina K, Hatanaka H, Bando M, Ohno S, Ishikawa Y, Aburatani H, Niki T, Sohara Y, Sugiyama Y and Mano H: Identification of the transforming $E M L 4-A L K$ fusion gene in non-small-cell lung cancer. Nature 448: 561-566, 2007.

2. Shinmura K, Kageyama S, Tao H, Bunai T, Suzuki M, Kamo T, Takamochi K, Suzuki K, Tanahashi M, Niwa H, Ogawa H and Sugimura H: EML4-ALK fusion transcripts, but no NPM-, TPM3-, CLTC-, ATIC-, or TFG-ALK fusion transcripts, in non-small cell lung carcinomas. Lung Cancer 61: 163-169, 2008.

3. Schmid K, Oehl N, Wrba F, Pirker R, Pirker C and Filipits M: $E G F R / K R A S / B R A F$ mutations in primary lung adenocarcinomas and corresponding locoregional lymph node metastases. Clin Cancer Res 15: 4554-4560, 2009.

4. Kohno T, Ichikawa H, Totoki Y, Yasuda K, Hiramoto M, Nammo T, Sakamoto H, Tsuta K, Furuta K, Shimada Y, Iwakawa R, Ogiwara H, Oike T, Enari M, Schetter AJ, Okayama H, Haugen A, Skaug V, Chiku S, Yamanaka I, Arai Y, Watanabe S, Sekine I, Ogawa S, Harris CC, Tsuda H, Yoshida T, Yokota $\mathrm{J}$ and Shibata T: KIF5B-RET fusions in lung adenocarcinoma. Nat Med 18: 375-377, 2012.

5. Takeuchi K, Soda M, Togashi Y, Suzuki R, Sakata S, Hatano S, Asaka R, Hamanaka W, Ninomiya H, Uehara H, Lim Choi Y, Satoh Y, Okumura S, Nakagawa K, Mano H and Ishikawa Y: RET, ROS1 and ALK fusions in lung cancer. Nat Med 18: 378-381, 2012.

6. Lipson D, Capelletti M, Yelensky R, Otto G, Parker A, Jarosz M, Curran JA, Balasubramanian S, Bloom T, Brennan KW, Donahue A, Downing SR, Frampton GM, Garcia L, Juhn F, Mitchell KC, White E, White J, Zwirko Z, Peretz T, Nechushtan H, Soussan-Gutman L, Kim J, Sasaki H, Kim HR, Park SI, Ercan D, Sheehan CE, Ross JS, Cronin MT, Jänne PA and Stephens PJ: Identification of new $A L K$ and $R E T$ gene fusions from colorectal and lung cancer biopsies. Nat Med 18: 382-384, 2012.

7. Matsuura S, Shinmura K, Kamo T, Igarashi H, Maruyama K, Tajima M, Ogawa H, Tanahashi M, Niwa H, Funai K, Kohno T, Suda T and Sugimura H: CD74-ROS1 fusion transcripts in resected non-small cell lung carcinoma. Oncol Rep 30: $1675-1680,2013$

8. Oxnard GR, Binder A and Jänne PA: New targetable oncogenes in non-small-cell lung cancer. J Clin Oncol 31: 1097-1104, 2013.
9. Casaluce F, Sgambato A, Maione P, Rossi A, Ferrara C, Napolitano A, Palazzolo G, Ciardiello F and Gridelli C: ALK inhibitors: a new targeted therapy in the treatment of advanced NSCLC. Target Oncol 8: 55-67, 2013.

10. Cappellen D, De Oliveira C, Ricol D, de Medina S, Bourdin J, Sastre-Garau X, Chopin D, Thiery JP and Radvanyi F: Frequent activating mutations of FGFR3 in human bladder and cervix carcinomas. Nat Genet 23: 18-20, 1999.

11. Greulich H and Pollock PM: Targeting mutant fibroblast growth factor receptors in cancer. Trends Mol Med 17: 283-292, 2011.

12. Cancer Genome Atlas Research Network: Comprehensive genomic characterization of squamous cell lung cancers. Nature 489: 519-525, 2012.

13. Singh D, Chan JM, Zoppoli P, Niola F, Sullivan R, Castano A, Liu EM, Reichel J, Porrati P, Pellegatta S, Qiu K, Gao Z, Ceccarelli M,Riccardi R, Brat DJ, Guha A, Aldape K, Golfinos JG, Zagzag D, Mikkelsen T, Finocchiaro G, Lasorella A, Rabadan R and Iavarone A: Transforming fusions of FGFR and TACC genes in human glioblastoma. Science 337: 1231-1235, 2012.

14. Williams SV, Hurst CD and Knowles MA: Oncogenic FGFR3 gene fusions in bladder cancer. Hum Mol Genet 22: 795-803, 2013.

15. Wu YM, Su F, Kalyana-Sundaram S, Khazanov N, Ateeq B, Cao X, Lonigro RJ, Vats P, Wang R, Lin SF, Cheng AJ, Kunju LP, Siddiqui J, Tomlins SA, Wyngaard P, Sadis S, Roychowdhury S, Hussain MH, Feng FY, Zalupski MM, Talpaz M, Pienta KJ, Rhodes DR, Robinson DR and Chinnaiyan AM: Identification of targetable FGFR gene fusions in diverse cancers. Cancer Discov 3: 636-647, 2013.

16. Majewski IJ, Mittempergher L, Davidson NM, Bosma A, Willems SM, Horlings HM, de Rink I, Greger L, Hooijer GK, Peters D, Nederlof PM, Hofland I, de Jong J, Wesseling J, Kluin RJ, Brugman W, Kerkhoven R, Nieboer F, Roepman P, Broeks A, Muley TR, Jassem J, Niklinski J, van Zandwijk N, Brazma A, Oshlack A, van den Heuvel M and Bernards R: Identification of recurrent FGFR3 fusion genes in lung cancer through kinome-centred RNA sequencing. J Pathol 230: 270-276, 2013.

17. Liao RG, Jung J, Tchaicha J, Wilkerson MD, Sivachenko A, Beauchamp EM, Liu Q, Pugh TJ, Pedamallu CS, Hayes DN, Gray NS, Getz G, Wong KK, Haddad RI, Meyerson M and Hammerman PS: Inhibitor-sensitive FGFR2 and FGFR3 mutations in lung squamous cell carcinoma. Cancer Res 73: 5195-5205, 2013.

18. Shinmura K, Goto M, Suzuki M, Tao H, Yamada H, Igarashi H, Matsuura S, Maeda M, Konno H, Matsuda T and Sugimura H: Reduced expression of MUTYH with suppressive activity against mutations caused by 8-hydroxyguanine is a novel predictor of a poor prognosis in human gastric cancer. J Pathol 225: 414-423, 2011.

19. Pao W and Girard N: New driver mutations in non-small-cell lung cancer. Lancet Oncol 12: 175-180, 2011.

20. Ulivi P, Romagnoli M, Chiadini E, Casoni GL, Capelli L, Gurioli C, Zoli W, Saragoni L, Dubini A, Tesei A, Amadori D and Poletti V: Assessment of EGFR and K-ras mutations in fixed and fresh specimens from transesophageal ultrasound-guided fine needle aspiration in non-small cell lung cancer patients. Int J Oncol 41: 147-152, 2012.

21. Mantripragada $\mathrm{K}$ and Khurshid $\mathrm{H}$ : Targeting genomic alterations in squamous cell lung cancer. Front Oncol 3: 195, 2013.

22. Pros E, Lantuejoul S, Sanchez-Verde L, Castillo SD, Bonastre E, Suarez-Gauthier A, Conde E, Cigudosa JC, Lopez-Rios F, Torres-Lanzas J, Castellví J, Ramon y Cajal S, Brambilla E and Sanchez-Cespedes M: Determining the profiles and parameters for gene amplification testing of growth factor receptors in lung cancer. Int J Cancer 133: 898-907, 2013

23. Intini D, Baldini L, Fabris S, Lombardi L, Ciceri G, Maiolo AT and Neri A: Analysis of FGFR3 gene mutations in multiple myeloma patients with $\mathrm{t}(4 ; 14)$. Br J Haematol 114: 362-364, 2001.

24. Petitjean A, Mathe E, Kato S, Ishioka C, Tavtigian SV, Hainaut P and Olivier M: Impact of mutant p53 functional properties on TP53 mutation patterns and tumor phenotype: lessons from recent developments in the IARC TP53 database. Hum Mutat 28: 622-629, 2007.

25. Yeudall WA, Vaughan CA, Miyazaki H, Ramamoorthy M, Choi MY, Chapman CG, Wang H, Black E, Bulysheva AA, Deb SP, Windle B and Deb S: Gain-of-function mutant p53 upregulates CXC chemokines and enhances cell migration. Carcinogenesis 33: 442-451, 2012.

26. Bromberg Y and Rost B: SNAP: predict effect of non-synonymous polymorphisms on function. Nucleic Acids Res 35: 3823-3835, 2007. 